\title{
Classification and Evaluation of Defense Mechanisms
}

\author{
Sumin Hong and Jee Hyun Ha \\ Department of Psychiatry, School of Medicine, Konkuk University, Seoul, Korea
}

\section{방어기제의 평가와 분류}

\author{
홍수민 · 하지현 \\ 건국대학교 의학전문대학원 정신건강의학교실
}

\begin{abstract}
A defense mechanism is an automatic psychological process that protects an individual from anxiety and internal or external risks or stressors. Defense mechanisms work largely in unconscious states and are associated with emotional conflicts and responses to internal and external stress. Applying specific patterns of defense would reflect the ego function level or maturation of each individual. Hence evaluation of defense mechanisms can offer valuable information for the psychodynamic understanding of patients. Authors have introduced the history of concepts of defense mechanisms, classification of defense, and various kinds of evaluation methods. These aspects can be classified into direct or indirect methods. Direct examinations comprise a direct evaluation by clinicians such as the Vaillant Defense Mechanism Rating Scale and a self-report method such as the Defense Style Questionnaire. Indirect examinations comprise a projective test such as the Rorschach test and objective tests such as the Minnesota Multiphasic Personality Inventory.

Psychoanalysis 2020;31(1):1-10
\end{abstract}

KEY WORDS: Defense mechanism · Psychometry $\cdot$ Evaluation $\cdot$ Adjustment.

Received: November 26, 2019 Revised: December 16, 2019 Accepted: December 21, 2019

Address for correspondence: Jee Hyun $\mathrm{Ha}, \mathrm{MD}$

Department of Psychiatry, School of Medicine, Konkuk University, 120 Neungdong-ro, Gwangjin-gu, Seoul 05029, Korea

Tel: +82-2-2030-7569, Fax: +82-2-2030-7748, E-mail: jhnha@naver.com

\section{서 론}

\section{방어기제의 정의}

방어기제란 심리 내적 또는 외적 사건으로 인해 발생한 불안감을 처리하고 심리 내부의 평형 상태를 유지하기 위해 자아의 무의식 영역에서 일어나는 심리기제다. 방어기제는 개인으로 하여금 일련의 사건들에 대한 인식을 변화시켜서, 내부 및 외부 환경의 갑작스러운 변화를 최소화하고 인지 부조화를 줄일 수 있게 하는 선천적이며 비자발적인 조절 과정이다(Vaillant 1971). 따라서 방어기제는 개인이 가지는 자기(self), 타인(others), 생각, 감정에 대한 지각을 변화시키 며 동시에 지키는 기능을 한다. 방어기제는 개인의 적응을 돕고, 동일한 스트레스 상황에서도 개개인이 다른 사고, 정 서, 행동 및 태도 등의 반응을 나타낼 수 있게 한다. 또한 방

This is an Open Access article distributed under the terms of the Creative Commons Attribution Non-Commercial License (https://creativecommons.org/licenses/by-nc/4.0) which permits unrestricted non-commercial use, distribution, and reproduction in any medium, provided the original work is properly cited.
어기제는 개인의 자원, 기술 또는 동기만으로 내적 갈등이나 외부의 위협으로부터 심신의 안녕을 지키기 어려울 때마다 현실을 왜곡하여 개인으로 하여금 비교적 안정적으로 상황 에 대응할 수 있도록 하는 일종의 행동 패턴이기도 하다(Ihilevich와 Gleser 1993). 방어기제는 모든 사람이 갖고 있는 것으로, 한 사람의 방어기제의 패턴을 관찰하면 그 사람에 대한 많은 정보를 얻을 수 있는 유용성이 있다. 이는 무의식 의 영역에서 작동하는 지속적인 자아(ego)의 기능이며 일생 을 통해 반복적으로 이용하며(Bond 등 1989), 개인이 사용 하는 방어기제의 종류는 성격에 따라 결정되며, 한 사람의 성격을 잘 반영한다(Vaillant 1976). 방어기제는 자아의 기능 을 반영하여 특정 방어기제들은 가장 미숙하고 원시적인 것 에서부터 성숙한 수준까지 다양하며, 어떠한 방어기제를 사 용하느냐에 따라 개인의 심리적 건강 상태를 어느 정도 알아 볼 수 있다. 특히 방어기제의 성숙도는 자아 기능의 중요한 특성으로서 삶의 여러 영역들에서 중요한 역할을 한다. 방어 기제의 성숙도는 IQ(Haan 1963), 심리사회적 성숙(Vaillant 등 1986), 사회적 상승 이동(Snarey와 Vaillant 1985) 등과 정 
적 상관이 있다. 정신분석적으로는, 방어기제의 평가는 특히 신경증적 환자와 인격장애 환자를 보다 잘 이해하기 위한 상당히 효과적인 방법 중 하나다. 저자들은 정신치료 및 정 신분석에 있어 자아의 기능 수준과 성격 파악에 용이한 수 단인 방어기제의 개념의 역사를 알아보고, 이를 평가하기 위 해 개발된 도구들을 조사해 보았다.

\section{방어기제 개념의 역사}

Sigmund Freud(1894)는 『The neuro-psychoses of defense (방어의 신경-정신증)」에서 방어라는 용어를 처음 사용했다. 그는 개인이 받아들이기 힘든 생각이나 감정으로부터 스스 로를 보호하기 위해, 무의식적인 과정에서 이러한 생각이나 감정을 왜곡시켜 혼란을 줄인다고 하였다. 그는 초기에 몇 가지 방어에 대해 기술하였지만 수년 동안 억압과 방어를 같은 의미로 사용했다(Moore와 Fine 1990). 그는 이후 구조 이론을 도입하면서, 방어가 무의식적 심리 과정이며 억압은 많은 방어 중에 하나임을 명확히 하였다(Freud 1926).

방어기제라는 용어는 Anna Freud(1937)가 『The ego and the mechanisms of defense(자아와 방어기제)」에서 처음 사 용했다. 안나 프로이트는 자아 기능이 방어적으로 사용되는 열 가지 활동들 또는 방법들에 대해 서술했다. 이때 제시된 것은 억압(repression), 반동 형성(reaction formation), 퇴행 (regression), 격리(isolation), 취소(undoing), 투사(projection), 자기에 대한 공격(agression against the self), 전치 (displacement), 부인(denial), 반전(reversal)이다. 그녀는 불 안의 원천이 되는 욕동, 외부 세계 및 초자아에 따라 방어를 분류할 것을 제안하였다. Anna Freud(1965)는 방어기제를 인간 심리의 정상적인 부분으로 확대하여 보면서 방어기제 의 발달적 측면에 집중하고, 한편으로 다양한 범위에서 방어 기제가 적응적이기도 하고 비적응적이기도 하다는 것을 밝 혔다. 안나 프로이트 이후 정신분석 이론에서 자아심리학이 중심이 되면서 방어가 내적 갈등과 환상에 의해 촉발된 결 과물이라는 초기 Sigmund Freud의 관점과는 달리 개인이 현실에 적응하는 정상적인 반응이자 인지 과정이라는 확대 적 인식이 주류가 되었다(Hartmann 1939).

Brenner와 Hartmann은 자아심리학의 관점에서 방어를 규정했다. Brenner(1981)는 Anna Freud(1937)가 주장했던 특정한 방어기제라는 개념의 유용성에 대해 의문을 제기했 다. 방어기제는 단독으로 또는 항상 변화하는 관계와 함께 작용하며, 다양한 행동, 생각, 정동, 성격 양상, 다른 자아 기 능들, 그리고 욕동을 사용한다. 즉 자아 기능의 모든 측면들 이 방어를 위해 사용될 수 있는데, 이렇게 복잡한 방어기제 의 작동 방식을 특정한 하나의 방어기제로 설명하는 것은
인간의 정신세계에서 자아가 기능하는 방식을, 방어기제를 이름으로 하여 지나치게 단순화할 위험이 있다고 본 것이다. 그는 방어를 정신 활동의 범위만큼이나 다양하고 광범위한 것으로 더 넓게 보는 태도로, 어떠한 정신 활동이나 자아의 기능도 방어로써 기능할 수 있다고 하였다. 그의 관점을 따 른다면 특수한 방어기제란 없고, 방어는 불안을 감소시키거 나 긴장을 감소시키는 효과의 측면에서만 정의될 수 있다. 그의 작업은 이전의 Hartmann 등(1964)의 작업과도 밀접한 관련이 있다. 이들은 욕동뿐만 아니라 외부 세계의 위급한 상황에 대처하기 위해 사용하는 다양한 자아 기능이 있고, 이 중에 방어도 하나의 기능으로 보았다. 여러 가지 방법을 이용하여 적응(adaptation)과 조절(accomodation)을 하는 기관으로 자아를 위치 지었다.

Vaillant(1971)는 방어기제를 불안이나 공격성과 같이 받 아들일 수 없는 충동이나 내적 갈등으로부터 개인을 보호하 는 동시에, 외부 현실, 욕구, 양심 및 대인관계 사이에 발생 할 수 있는 갈등을 중재하고 조정하는 심리적 기제라고 정 의하였다. 즉, 한 개인이 갑작스러운 내부 및 외부적인 스트 레스에 직면했을 때 심리적 안정성을 유지하기 위해 나타나 는 무의식적이고 자동적인 노력이라는 것이다. 자아의 방어 기제는 현재의 정신건강 수준을 보여주는 강력한 지표이며 (Vaillant와 Schnurr 1988), 미래의 정신건강을 예측할 수 있 는 좋은 예측 요인으로도 평가된다(Vaillant와 Vaillant 1990). 또한 방어기제는 개인의 심리사회적인 적응과도 밀접한 관 계가 있다(Vaillant 1975).

방어에 대한 초기 이론들은 방어가 불안을 일으킬 수 있 는 욕동이나 소망이 의식되지 않도록 하여 심리 내적 평형을 유지하는 기능에 대해 보다 초점을 둔다. 반면 대상관계 이 론, 자기심리학 이론 등을 중심으로 발전한 후기 방어 이론 에서는 방어를 더 이상 특정한 갈등이나 충동에 반하여 사 용되는 것으로 엄격하게 개념화하지 않는다. 이들에 따르면 방어는 중요한 대상과의 친밀한 관계 속에서 발생하는 관계 적이고 인지적인 패턴의 일부이다. 따라서 방어기제는 불안 을 야기할 수 있는 생각 또는 생각을 의식하게 되는 그 자체 로부터 개인을 보호하기보다는, 개인의 자존감을 보호하는 것으로 간주된다(Cooper 1998). 방어기제들은 고통스러운 정동으로부터 자기를 보호한다는 동일한 기능을 갖는 한편, 그 목적을 성취하는 방식은 각각 다르다. 예를 들어 퇴행은 이전 단계의 심리 구조로 되돌아가며, 내사와 동일시는 위협 적인 것을 자기 내부로 받아들이는 것을 통해서, 부인은 위 협적인 상황이 마치 존재하지 않는 것처럼 생각하는 것을 통해서, 승화는 수용할 수 없는 욕동의 형태를 수용 가능한 것으로 바꾸는 것을 통해서 방어 기능을 수행한다. 또한 방 
어는 행동과 사고를 더 효율적으로 만드는 건설적인 기능을 수행할 수도 있다. 이것을 적응적 기제(adaptive mechanisms) 또는 자율적 자아 기능(autonomous ego functions) 이라고 부른다. 예를 들어 고립은 정서와 사고를 분리시킴으 로써 연관된 정서가 야기할 수 있는 혼란을 피할 수 있게 하 고, 생각을 보다 논리적으로 전개할 수 있도록 돕는다(Moore 와 Fine 1990). 여러 학자들은 방어가 적응적인 기능을 지닌 다는 점을 강조하였다. Willick(1995)에 따르면 방어란 불안 을 유발하는 욕동이나 불쾌한 정동으로부터 자아를 보호하 기 위해 사용되는 정상적인 조작이다. 방어는 주로 심리적인 갈등에서 비롯되는데, 정상적인 적응과 성격 발달의 부분이 될 수도 있고 병리적인 증상이나 성격 특성과 관련될 수도 있다. 방어는 성격 발달, 증상 형성, 심리적 생활의 모든 측 면에서 역할을 하며, 방어가 경직되고 지속되면 병리적이라 고 본다. Vaillant(1971)는 방어기제는 오랜 기간 반복적인 패턴으로 수집될 필요가 있으며, 그 적응적인 기능을 고려해 야 함을 강조하였다.

많은 현대 정신분석 치료자들은 방어의 초기 및 후기 이 론들을 통합하고 있다(Cooper 1998). 종합해 보면 방어기제 는 단지 내적 욕동이나 소망의 의식화를 억압하는 과정이 아니라, 스트레스에 대한 개인의 무의식적 또는 인지적 적응 및 대처 방법이라는 관점에서 이해해 볼 수 있다. 여러 방어 기제들은 모두 고통스러운 정동으로부터 자기를 보호한다 는 동일한 목적이 있겠으나, 개인의 자아 기능, 대상관계, 대 인관계, 성격 양상 등에 따라 다양한 방어기제가 사용될 수 있으며 이는 광범위한 인간의 행동을 설명하는 데 중요하다. 임상적으로 방어기제의 측정은 개인의 적응 능력과 대처 기 술을 측정 및 예측한다는 점에서 유용하게 활용될 수 있을 것으로 보인다.

\section{방어기제 분류의 시도 및 필요성}

Anna Freud(1937)로부터 시작하여 약 50년간 여러 학자 들은 방어기제를 체계화할 필요성에 대해 지속적으로 강조 해 왔다(Engel 1962; Lazarus 1983; Menninger 등 1963). 그 러나 이들 모두 서로 다른 명명법을 사용한 점, 연구의 경험 적 증거가 부족한 점으로 인해 신뢰도 높은 방어기제의 체계 화는 좀처럼 이뤄지지 않았다. Anna Freud(1937)는 『자아와 방어기제」에서 방어기제의 목록을 제시하였다. 먼저 억압, 퇴행, 반동 형성, 전위, 투사, 격리, 취소, 부인, 자기에 대한 공격, 반전을 제시하였고, 이후 공격자에 대한 동일시, 이타 적 양도를 추가하였다. 그녀는 불안의 원천, 즉 욕동의 강도, 외부 세계 및 초자아에 따라 방어를 분류할 것을 제안하였다.

이후 Haan(1963)의 종단 연구, Cooper(1992)의 자아 프로
파일 척도(Ego Profile Scale) 등 방어기제에 대한 여러 경험 적인 연구들이 이뤄졌지만 이들은 충분히 타당화되지 못하 였고, 방어기제에 대한 경험적 이해는 여전히 개념적 혼란 상태에 있었다. 이러한 이유로 Diagnostic and Statistical Manual of Mental Disorders third edition(DSM-III)까지는 방어기제가 하나의 축(axis)으로서 포함되지 못하였다(Cooper 1992; Vaillant 등 1986). Kernberg(1970)는 방어기제를 정신병적, 경계성, 신경증적 기능 수준으로 분류하는 가장 널리 사용되는 체계를 제안했다.

Vaillant(1971)는 발달과 성숙의 관점에서 방어기제를 연 구했다. 그는 방어를 성숙도에 따라 분류할 수 있으며 미숙 한 방어가 발달 과정에서 성숙한 방어로 진화한다고 보았다. 그는 부정(denial)은 아이가 스트레스와 갈등에 더 유연하고 전략적으로 대처하는 법을 배움에 따라 억압(repression)으 로 발전하는 것으로, 성인기에는 일반적으로 억압으로 대체 된다고 했다. 예를 들어 유아기에는 심한 스트레스 상황에 놓일 경우 정신증적 부정(psychotic denial)을 끌어내지만, 청소년기에는 억압이나 해리로 나타나며, 성인기에는 억제 로 나타난다. 이와 같이 각각의 방어를 성숙과 발달의 과정 에서 시기별로 정상적으로 나타났다가 다른 성숙한 방어로 대체되는 것으로 분류했다. 그러나 원시적인 방어가 특정 시 기 이후에 완전히 사라지는 것이 아니며, 발달 과정에서 문 제가 생길 경우에는 미숙한 방어가 잔존하기도 하고, 정상 발달을 하더라도 심한 스트레스가 생길 경우에는 미성숙한 방어가 재발현되는 퇴행이 가능하다고 했다. Vaillant(1971) 는 이런 개념에 기반해서 18 개의 방어기제를 성숙도에 따라 자기애적(narcissistic), 미성숙한(immature), 신경증적(neurotic), 성숙한(mature)의 네 가지 유형으로 분류하였다. 그 는 각각의 방어 유형이 개인의 정신병리와 체계적으로 관련 돼 있어, 자기애적 유형은 정신증(psychosis)과, 미성숙 유형 은 성격 문제 및 정동장애와, 신경증적 유형은 신경증과, 성 숙한 유형은 성인의 대응기제(coping mechanism)와 연관이 있다고 하였다. 그는 30년간 30명의 남성을 대상으로 한 심 리적인 건강에 대한 연구에서 방어의 위계 개념이 타당하며, 전 생애에서의 적응과 방어기제 선택 사이에 연관성이 반드 시 존재한다고 했다(Vaillant 1971). 이후에도 경험적 연구를 통해 방어 유형과 개인의 정신병리와의 상관관계를 밝혔고, 개인의 주요 방어기제가 일관성 있게 유지되며 방어기제가 성격 유형의 한 행동 표현임을 제안하였다(Vaillant 1976). 그 러나 방법론적 한계와 문화적 차이 등을 감안할 때 일반화에 는 상당한 제한점이 있다.

1990년대에는 방어기제의 체계화와 관련한 여러 경험적 연구들이 축적되면서(Cramer 1991; Skodol과 Perry 1993), 
방어가 상대적인 정신병리의 수준에 따라 나눠질 수 있다는 것이 알려졌다. 위의 연구 결과 DSM-III에서 분류한 자아 방어기제 중 미성숙한 방어는 인격장애의 상당 부분 기저를 이룬다는 것이 밝혀졌다. 그리고 특정 방어기제 사용이나 방 어 유형에 남녀의 차이가 존재하는 것이 알려졌다(Cramer 1987, 1991; Ptacek 등 1994; Hibbard와 Porcerelli 1998; Mahalik 등 1998; Watson과 Sinha 1998; Watson 2002; $\mathrm{Pe}^{-}$ traglia 등 2009; Furnham 2012). 여성은 신체화와 같이 내면 화하는 방어기제를 사용하는 경향이, 남성은 행동화와 같이 외현화하는 방어기제를 사용하는 경향이 있었고 이는 초기의 방어기제의 일반론과는 상응하는 면이었다(Deutsch 1944; Erikson 1964).

현대 심리학에서 가장 널리 사용하는 방식은 미숙한 방어에 서부터 성숙한 방어 순서로 체계화하는 것이다. 이는 Vaillant 의 분류 방식과 유사하다. 이에 따르면 원초적 또는 자기애 적 방어에는 망상적 투사, 부정, 왜곡이 있으며, 미성숙한 방 어에는 투사, 조현형 환상, 건강염려증, 수동-공격적 행동, 행동화가 있다. 신경증적 방어에는 지식화, 억압, 전치, 반동 형성, 해리가 있으며, 성숙한 방어에는 이타주의, 유머, 승화, 억제가 있다.

방어기제에 대한 평가는 주로 면담을 통해 임상적인 판단 하에 이루어져 왔다. 그러나 이러한 평가는 임상가의 수준, 치료자-환자 간의 치료적 동맹 수준, 임상가 개개인의 면담 방식에 따른 차이가 있어 평가 결과의 일관성이 떨어질 수 도 있다는 단점이 있다. 따라서 이를 극복하기 위해 보다 신 뢰도와 타당도가 높은 방어기제 평가 척도를 개발하기 위한 시도가 있었다.

이와 관련하여 저자들은 방어기제를 측정하는 여러 심리 학적 검사의 종류를 나열 및 각각의 검사 방법에 대해 설명 하고, 한국어 번역본 및 타당화 연구의 유무를 파악하고자 한다. 이를 통해 치료 환경에서 환자의 방어기제와 치료 경 과를 평가할 때 사용할 수 있는 검사들에 대한 전반적인 정 보를 제공하여, 치료자가 적절한 검사 도구를 선택하는 데 있어 도움을 주고자 한다.

\section{본 론}

\section{방어기제의 평가}

방어기제는 원칙적으로 무의식적인 수준에서, 자동적인 반응으로 작동하기에 의식 차원에서 자신의 방어기제를 평 가하거나, 행동 관찰을 통해 평가하는 것은 많은 제한점과 어려움이 있다. 더욱이 특정 욕동의 파생물이나 정동의 부재 또는 왜곡으로부터 개인의 방어기제를 유추해야 하는 어려
움도 있다. 임상에서는 자가보고 검사, 면담을 통한 분석적 검사, 투사적 검사가 일반적으로 사용되고 있으나, 각각의 검 사가 방법론적인 문제를 지니고 있는 것은 사실이다(Beutel 1988). 저자들은 현재 임상에서 사용하는 방어기제 평가 도 구를 크게 직접적 검사와 간접적 검사로 나누어 제시할 것이 다. 직접적 검사에는 임상가가 직접 면담하는 방식과 자가보 고 방식이 있으며, 간접적 검사에는 투사적 검사와 객관적 검사가 있다.

\section{면담을 통한 평가}

면담을 통한 방어기제 분석은 전통적으로 임상가들이 취 해 온 방식이다. 방어기제가 개인의 무의식 수준에서 일어나 는 과정이라는 점에서, 임상가와의 상호 관계를 통해 피검자 의 무의식적인 행동의 경향성을 분석하여 피검자 자신은 인 식하지 못하는 방어기제를 유추해 낼 수 있다는 것이 이 방 식의 가장 큰 장점이다.

Haan(1965)은 미네소타 다면적 인성검사(Minnesota Multiphasic Personality Inventory, MMPI) 항목을 이용하여 방 어기제에 대한 평가 척도를 개발하였다. 이 척도는 숙련된 임상의사와 면접관이 Oakland Growth Study에 참여한 49 명의 남성과 50 명의 여성을 평균 12 시간 면접한 내용의 요 약 사본을 검토한 후에 개발하였고, 총 10 개의 방어기제와 10 개의 대처기제를 평가한다. Haan의 평정 방식은 방어기 제에 대한 경험적 연구를 진일보했다는 점에서, 그리고 방어 유형과 대처 유형에 대한 정의를 내림으로써 각 유형과 정 신건강 측정치와의 상관을 조사했다는 점에서 의미가 있다. 그러나 방어를 지나치게 특이하게 정의하고, 표집과 평정자 신뢰도에 문제가 있다는 지적을 받는다.

단어연상검사(word association test)는 Carl Gustav Jung 이 1908년 Friedrich Wilhelm Kaeding의 빈도 사전에 의거 하여 최다 빈도의 단어 100 개의 자극어를 택하여 만든 검사 이다. 먼저 피분석자에게 100 개의 자극어를 한 번 읽어 준 다음, 첫 번째로 떠오르는 단어를 애기하도록 한다. 검사자 는 이 과정에서 피분석자가 반응하는 데까지 걸리는 시간, 언어 및 비언어적인 반응을 분석한다. 이 검사는 통계적 연 구 도구나 진단적 검사라기보다는, 분석 과정에서 피분석자 의 무의식적인 콤플렉스를 환기시켜 이를 의식화시키는 도 구로써 쓰이고 있다. 콤플렉스의 진단을 목적으로 하는 단어 연상검사는 비교적 보편성을 띠고 있으나, 다른 한편으로는 이를 적용하는 지역의 문화적 특수성에 좌우될 수 있다. 따 라서 국내에서는 자극어를 한국인에게 친숙한 단어로 재편 성하고, 제시어를 50 개로 축약하여 검사 시간을 단축한 이서 단어연상검사가 개발되어 사용 중이다(Suh 1995). 
Vaillant(1976)는 대학생 95명에 대해 30년간에 걸쳐 생활 일화 방법을 이용하여 자아 방어기제의 선택과 성인 적응 간의 관계를 연구하였다. 전반적인 방어 성숙도는 객관적인 정신병리를 측정하는 척도와 부적인 상관을 보였고, 외부 환 경에 대한 객관적인 적응과 정적인 상관을 보였다. 미성숙한 방어는 좋은 적응과 부적으로 상관되었으며, 정신병리와 정 적으로 상관되었고, 성숙한 방어는 반대였다. 방어기제의 전 반적 성숙도는 결혼의 안정성, 직업의 안정성, 주관적인 행 복 및 신체적 건강과 상관있었다. 그는 미성숙 방어가 신체 적 건강이 저하되어 발생한 결과물이 아니라, 선행 변인이라 는 결과를 보고하였다. Vaillant의 방어기제 평정 척도(Vaillant Defense Mechanism Rating Scale, VDMRS)는 국내에 서 Korean-VDMRS(K-VDMRS)로 번안, 재구성 및 타당화 연구가 시행되었다(Kim과 Ko 2018). K-VDMRS는 Vaillant가 제시한 방어기제 수준의 위계에 기초해 피검자의 방 어 성숙도를 성숙한 방어, 신경증적 방어, 미성숙한 방어의 세 수준으로 평가한다. 임상가의 면담으로 이뤄지며 직업, 가족, 건강, 심리에 관한 51 개의 질문으로 구성되어 있고 약 1 시간이 소요된다. 기본적으로 면담 과정에서 피검자는 "스 트레스를 받을 때 어떻게 대처하는 편입니까? 그리고 그렇게 했을 때 효과는 어떠합니까?" 혹은 "윗사람과의 관계에서 좋 은 점과 불편한 점은 무엇입니까?" 등 일상생활에서 직면하 게 되는 다양한 상황에 대해 질문을 받게 된다. 결과적으로 방어기제 사용이 현저한 경우에는 '주요'라고 평정하고 2점 을 부여하며, 방어기제가 관찰되지만 방어의 사용이 현저하 지 않은 경우는 ‘부수’라고 평정하고 1점을 부여한다. 1 시간 의 인터뷰 내용을 바탕으로 평가했을 때, 방어기제가 관찰되 지 않는다고 판단되는 경우에는 '존재하지 않음'으로 평정하 고 0 점을 부여한다.

Perry(1990)는 Vaillant에 이어 다양한 종류의 자료에 적용 할 수 있는 방어기제 평정 척도(Defense Mechanisms Rating Scale, DMRS)를 고안하였다. 이 검사는 임상 면접이나 치료 기록, 비디오, 오디오 녹음 기록을 이용해 방어기제를 측정 하는 방법이며, 주로 정신치료에서 치료 경과에 따른 방어기 제의 변화, 방어기제에 따른 치료 순응도 등을 평가하는 데 사용된다(Drapeau 등 2003; Johansen 등 2011; Kramer 등 2009). DMRS는 27개 방어기제 각각에 대해 정의, 심리 내적 기능, 다른 방어와 구별하는 방법 및 구체적 예가 제시되어 있다. 유사한 기능적 속성 및 경험적 관계에 근거해서 7개의 방어 수준으로 구분되어 7개의 방어 수준 점수가 산출된다. 마지막으로 방어 수준 위계에 따라 가중치가 계산된 전반적 인 방어적 기능 점수를 산출한다. DMRS에서는 상대적으로 미성숙한 수준의 방어에 많은 비중이 주어졌기 때문에, 이
척도를 사용한 연구들에서는 방어기제와 심리사회적인 적 응과의 연관성보다는, 성격장애나 우울장애와 같은 정신병 리와 방어기제 사이의 관계를 밝히는 데 유용하다.

Bauer와 Rockland(1995)는 방어 관련 행동 척도(The Inventory of Defense-Related Behaviors, IDBR)라는 것을 개 발했다. 이 척도는 평가자들로 하여금 방어 자체보다는 방어 의 징후로 간주되는 행동의 유무에 대해 조사하는 것이 특 징이다. 면담을 통해 환자가 보여주는 행동의 유형에 대해 평가하는 총 60 개의 항목으로 구성된다. IDBR은 전체 정신 치료 과정뿐만 아니라 단일 치료 세션 동안 방어 기능의 변 화를 평가하거나, 특정 진단을 하는 데 특정한 방어기제가 특 이점이 있다는 것을 밝히는 데 유용한 도구로 쓰인다(Conte 와 Plutchik 1995).

\section{자가보고를 통한 평가}

면담식 평가는 임상가의 주관성이 배제될 수 없다는 점에 서 평가 방법의 신뢰도 및 일관성이 떨어지고, 평가 시기에 따라 결과가 달라질 수 있다는 점, 무엇보다도 평가에 시간이 많이 소요된다는 단점이 있다. 특히 평정자들 간에 방어기제 평정의 신뢰도가 낮다는 것이 큰 문제다(Vaillant 1992). 이 를 보완하기 위한 것이 자가보고식 평가다. 자가보고식 평가 는 검사 신뢰도가 높으며, 소요 시간이 단축된다는 장점이 있다. 반면 피검자의 자가보고만으로 평가를 하는 것으로 임 상가와 상호작용에서 나타나는 무의식적 행동의 경향을 관 찰할 수 있는 기회가 없다. 무엇보다 자가보고란 의식적으로 처리된 결과물이기에 이것이 방어기제를 정확히 반영하고 있는지에 대한 반론이 있을 수밖에 없다. 이에 대해 Bond 등 (1983)은 방어기제가 이뤄지는 무의식적 정신 과정에 대한 직접적인 자기 보고는 불가능하지만, 무의식적 과정의 의식 적 파생물들에 대한 피검자의 의식적 자각은 가능하며, 자가 보고도 가능하다는 견해를 제시했다. 면담을 통한 직접적인 평가는 아니나 무의식적 과정으로 인해 파생된 결과물을 자 가보고로 충분히 평가 가능하다는 것이다.

Gleser와 Ihilevich(1969)는 방어기제를 공격적 방어, 투사 적 방어, 지식화된 방어, 직감적 방어, 억압적 방어인 총 5 개 의 유형으로 분류하였다. 이들에 의해 개발된 방어기제검사 (Defense Mechanism Inventory, DMI)는 1970년대에서 1990 년대 중반까지 5 가지 방어 유형을 연구하는 데 활발히 쓰였 다. DMI는 총 5 개 유형의 갈등(상황, 권위, 독립, 경쟁, 남성 성 또는 여성성)에 대해 각각 두 일화씩 총 10 개의 일화로 구성되어 있다. 피검자는 각 일화를 읽은 후 아래와 같이 네 가지 질문에 답하도록 요청받는다: 1) 당신의 실제 반응은 어떨 것 같은가? 2) 충동적으로(상상에서) 무엇을 하고 싶은 
가? 3) 어떤 생각이 날 수 있는가? 4) 어떠한 방어기제와 사 고방식이 느껴지고, 그 이유는 무엇인가? 각 질문에 대해 다 섯 가지 선택지가 주어지며, 각각은 다섯 가지 방어기제 중 하나에 해당한다. 따라서 피검자는 총 200개의 선택 항목에 응답하게 된다. DMI의 가장 최근 버전을 이용한 $\mathrm{DMI}-\mathrm{al}-$ ternative form이 Zhang(2015)에 의해 구성되었고, 이에 대 한 신뢰도 및 타당도 연구가 시행되었다.

이화방어기제검사(Ewha Defence Mechanisms Test, $\mathrm{EDMT}$ )는 Kim 등(1991)이 개발하였다. 이들은 자아 방어기 제가 개인의 성격과 적응을 이해하는 데 주요한 기본 요소 임을 전제로, 한국의 전래 속담을 기초로 하여 검사를 구성 하였다. 앞서 이-서 단어연상검사와 달리 외국의 검사를 번 안하지 않고 각각의 타당화 이론을 근거로 하였으며, 속담을 바탕으로 한 문항들이 포함되어 있어 한국인들의 의식 및 무의식적 행동을 이해하는 데 장점이 있다. 속담 내용을 기 초로 하되 속담을 일상적인 평이한 말로 바꾸어 상식과 같 은 지식이나 학력에 따른 반응에 의한 오류를 보정한 것이 특징이다. 총 200 개의 자가보고 문항으로 총 20 가지의 방어 기제 척도를 평가하며, 척도마다 10 개 문항이 있다. 척도별 점수 범위는 5 50점 사이이며 점수가 높을수록 해당 방어기 제를 두드러지게 사용하는 것으로 해석한다. 성숙 수준에 해 당되는 방어기제는 억제, 예상, 이타주의, 승화, 유머이며, 신 경증 수준에 해당되는 방어기제는 허세, 반동 형성, 전치, 해 리, 이지화이다. 또 미성숙 수준의 방어기제는 동일시, 수동 공격, 투사, 행동화, 퇴행, 부정이다.

Defense style questionnaire(DSQ)는 Bond(1992)에 의해 개발된 검사이다. 이 검사의 저자들은 방어기제 자체를 측정 하는 것은 신뢰도가 떨어진다고 판단해 전반적 방어의 유형 (style)을 측정하는 것을 목표로 하였다. DSQ는 25 개의 방어 기제를 측정하는 78 개의 문항과 응답의 사회적 바람직성 (social desirability) 정도를 측정하는 10개의 하위 문항으로 이루어져 있다. 방어에 대한 자가보고식 측정이 가능할 뿐만 아니라, 방어 유형 질문지를 통해 성숙성 위계에 따라 서로 구분되는 방어 유형들을 확인하는 것이 가능하다(Andrews 등 1989; Vaillant 등 1986). Bond와 Wesley(1996)는 DSQ를 사용한 수많은 연구들을 개관하면서 DSQ에 의해 측정되는 방어 유형이 여러 가지 정신건강 지표 및 성격적 특질들과 관련된다고 밝혔다. 특히, $\mathrm{DSQ}$ 는 성공적인 치료가 방어 유 형의 변화로 귀결되는 것을 밝혀 임상적 타당성이 있는 것 으로 평가된다. Cho(1999)가 DSQ를 토대로 한국판 방어 유 형 질문지(Korean-DSQ, K-DSQ)를 개발하고 타당화하였 다. K-DSQ는 방어기제에 대한 측정의 신뢰도를 높이기 위 해 3 개 미만의 측정 문항을 갖는 방어기제들과 방어기제를
직접 측정하지 않는 10 개의 허위 문항들을 제외하고, 문항방어기제 간 상관이 낮은 문항을 제외하여 원 척도의 총 88 문항에서 65 문항짜리 질문지로 축소했다.

\section{투사적 검사}

투사적 검사는 방어기제 평가 중 간접적인 검사로 방어기 제를 통해 파생된 행동을 평가하는 것으로 평가하는 간접적 방법이다. 투사적 검사는 객관적 검사에서 밝힐 수 없는 심 층적인 심리 내적 정보를 얻을 수 있기 때문에 개인의 정신 역동의 평가에 중요하다. 그러나 검사자의 주관적 해석 기술 이 결과에 많은 영향을 미치고 검사 방법에 대한 표준화가 힘 들어서 객관적 검사와 비교할 때 신뢰도나 타당도에 대한 명 확한 검증에 약점이 있다. 이를 현실에 적용을 할 때 응답 결 과의 분석에 고도의 기술을 요한다는 실제적 어려움이 있다. 가장 대표적인 검사인 로르샤흐 검사(Rorschach inkblot test) 에 대해서 연구자들이 다양한 접근 방식으로 연구한 바 있다 (Beck 1937; Hertz 1938; Piotrowski 1947). 이후 Exner(1986) 가 검사의 객관화와 표준화를 위해 이들의 다양한 채점 방 식을 통합하여 체계화하기도 하였으나, 여전히 극복하지 못 하는 여러 문제점이 있다. 그럼에도 로르샤흐 검사와 주제통 각검사(thematic apperception test, T.A.T)는 현재 임상에서 가장 널리 사용되고 있는 심리 검사다.

로르샤흐 검사는 스위스의 정신과 의사인 헤르만 로르샤 흐(Hermann Rorschach)가 1921년에 개발한 성격검사 방법 으로, 좌우 대칭의 잉크 얼룩이 있는 열 장의 카드로 이루어 져 있다. 피검사자에게 형태가 뚜렷하지 않은 카드의 그림을 보여주면서 무엇처럼 보이는지, 무슨 생각이 나는지 등을 자 유롭게 말하도록 한다. 검사자는 피검사자가 자신의 반응을 어떻게 구성하고 조직하는지, 자극을 어떻게 지각하고 어떠 한 설명을 부가시키는지 관찰한다. 반응 양상은 바로 개인의 동기, 갈등 및 방어와 관련되며, 성격의 특징적인 측면을 반 영한다. 일부 반응들은 분명히 정형화되거나 문화적으로 결 정된 것이지만, 또 다른 반응들은 의식적 태도나 무의식적인 면에서 피검사자의 독특한 면들을 드러낸다. 특히 반점의 형 태나 모양에 대한 반응을 보는 '형태(form) 반응'은 일반적 으로 지적인 활동과 동등하게 여겨지며 특히 지적 통제력, 지각의 명료성, 현실 접촉 및 자아 강도를 나타내는 것으로 본다. 또한 얼룩 반점을 사람으로 보았는지, 동물로 보았는 지, 해부학적인 것으로 보았는지, 자연 사물로 보았는지 등 을 분석하여 정신 내용을 감지하는 것은 정신분석학적 의미 로 해석할 수 있다. 무엇보다도 피검사자는 애매한 자극에 대해 자신의 반응이 갖는 의미를 알지 못하기 때문에, 객관 적 검사에 비하여 성격적 측면이 더 자유스럽고 덜 왜곡되 
며, 의식적인 통제를 덜 받게 된다(Shin 1989).

주제통각검사(T.A.T)는 투사적 기법 중 로르샤흐 검사 다 음으로 가장 많이 사용되는 검사로 Morgan과 Murray(1935) 에 의해 처음 개발되었다. 총 30 장의 그림과 1 장의 공백 카 드로 구성되어 있으며, 피검사자의 성별과 나이에 따라 카드 를 달리 조합하여 19 장의 그림과 1장의 공백 카드를 제시한 다. 대부분 그림에 사람이 그려져 있고, 각 인물의 행동이나 기분이 분명하게 표현된 정도가 각기 다르다. 로르샤흐 검사 와 마찬가지로 개인에 따라 다양한 반응을 이끌어낼 수 있 지만, 부분적으로는 구조화되어 있다는 것이 다른 점이다. 검사자가 각 카드를 제시하며 현재 어떤 일이 일어나고 있 는지, 과거에는 어땠는지, 카드의 인물이 어떻게 생각하고 느끼고 있는지, 앞으로 어떻게 될 것인지 이야기하도록 한 다. 피검사자가 자신의 성격적 측면을 이야기 속에 투사하 고, 해당 인물들과 자신을 동일시할 것이라는 점을 가정한 것 이다. T.A.T의 기본 가설은 정신 결정론(psychic determinism)으로서, 자극에 대한 반응은 결국 심리적 과정의 결과로 본다. Murray는 그림 자극에 대해 피검사자가 가져오는 주 제는 "욕구(need)와 압력(pressure)의 결합이며 개인과 환경 의 통일이며 실생활에서 생기는 여러 가지 사건의 역동적 구 조”라고 하였다(Morgan과 Murray 1935). 개인의 욕구와 환 경이 갖는 객관적 압력에 의해 나타난 주제를 통해 역동적 정신분석이 가능하다는 것이 T.A.T의 기본적 가설이라고 볼 수 있겠다(Shin 1989). 분석 방법에 대해서는 Morgan과 Mur$\mathrm{ray}(1935)$ 가 그의 성격 이론에 근거하여 제시한 분석 방법, Bellak(1971)의 T.A.T 분석표 등이 있지만, 실제 임상가들이 해석하는 방식은 보다 자유롭다. Cramer(2000)는 T.A.T를 이용한 방어 평가 방법(Defense Mechanism Manual)을 사 용하여 방어를 독립적으로 평가하였고, 미성숙한 방어를 많 이 사용할수록 간이정신진단검사의 전체심도지수(global severity index)가 높았다고 보고하였다.

실제 활용에 있어서 T.A.T의 그림에 등장하는 인물이 외 국인이라는 것은 한국인을 대상으로 적용할 때 제한점이 된 다는 지적도 있다(Shin 1989).

\section{객관적 검사}

객관적 검사는 간접적인 검사에 해당하는데, 투사적 검사 에 비해 검사자의 주관적인 해석이 배제될 수 있는 장점이 있어 객관적 검사라고 불리우기도 한다. 이 중 MMPI는 임 상에서 가장 널리 사용되고 있는 객관적 성격 검사로, 1940 년 심리학자인 Hathaway와 정신과 의사인 Mckinley가 환 자들의 임상 진단에 관한 정보 제공을 목적으로 개발했다 (Hathaway와 McKinley 1940), 국내에서는 1960년대 초반
부터 사용하기 시작하였고, Jung 등(1965)이 표준화를 실시 하였고, 이후 1989년에 2차 표준화 작업을 하여 지금까지 사 용하고 있다.

Trimboli와 Kilgore(1983)는 'MMPI 해석의 정신 역동적 접근'에서 MMPI의 특정한 성격 척도가 개인의 전형적인 방 어기제를 반영한다고 가정하고, 여섯 가지 성격 척도별로 대 표적인 방어기제를 제시하였다. 이 연구에서는 MMPI의 3, $4,5,6,9,0$ 하위 척도를 성격 척도, $1,2,7,8$ 을 증상 척도라 했고, 이들 중 성격 척도가 방어기제와 관련되어 있다고 보 았다. 예를 들어 $\mathrm{Hy}(3)$ 척도는 히스테리적 전환과 고전적 전 환의 특성을 나타내며, 억압의 방어기제와 연결된다. $\operatorname{Pd}(4)$ 척도는 적대적이고 공격적인 대인관계를 대표하며 외현화, 행동화, 합리화, 주지화 등의 방어기제를 통해 불안을 처리 한다. $\operatorname{Mf}(5)$ 척도에서는 남성의 높은 점수, 여성의 낮은 점 수가 여성성을 나타내는데 이는 억제라는 의식적 방어기제 와 관련이 있다. 반대의 경우 남성성을 나타내는데 이럴 경 우 공격성으로 불안에 대처하는 경향이 있다. $\mathrm{Pa}(6)$ 척도는 의심과 내적 민감성, 엄격한 태도 등을 나타내는데, 투사나 외현화 기제와 관계된다. $\mathrm{Ma}(9)$ 척도는 긴장성 우울, 기질적 뇌증후를 암시하며, 부정과 행동화와 연관된다. $\mathrm{Si}(0)$ 척도는 사회적 상황에서 민감도와 순종, 내향성을 나타내며, 회피와 위축을 통해 불안을 다룬다고 보고했다.

국내에서도 MMPI의 하위 척도들과 자아 방어기제와의 관 계를 살펴본 바가 있다. Pae(1993)는 MMPI의 각 하위 척도 와 방어기제와의 관련성을 연구하였다. $\mathrm{Hs}(1)$ 척도는 신체화, $\mathrm{D}$ (2) 척도는 신체화와 회피, $\mathrm{Hy}$ 척도는 신체화, $\mathrm{Pd}$ 척도는 투 사와 신체화. $\mathrm{Mf}$ 척도는 남성의 경우 신체화, 여성의 경우 왜 곡과 이타주의 기제와 상관이 있었다. 또한 $\mathrm{Pa}$ 척도는 투사, 해리, 신체화, $\mathrm{Pt}(7)$ 척도는 회피와 신체화, $\mathrm{Sc}(8)$ 척도는 신체 화, 회피, 투사로, $\mathrm{Ma}$ 척도는 행동화, 왜곡, 신체화, 유머, 수 동 공격, 퇴행으로, 그리고 마지막으로 $\mathrm{Si}$ 척도는 회피, 해리 기제와 연관된다고 보았다. Jun과 Park(1995)은 MMPI 각 하 위 척도에 따른 방어기제가 아닌, MMPI의 프로파일 유형에 따라 의미 있게 사용되는 방어기제들이 어떻게 다른지 알아 보고자 하였다. 이들은 대학생 330명을 대상으로 MMPI와 이화방어기제검사(EDMT)를 실시하여 정상 집단, 신경증적 프로파일 집단, 정신증적 프로파일 집단으로 구분하고, 각 프로파일 유형에 따라 주로 어떤 자아 방어기제들을 사용하 는지, 그리고 각 집단이 보이는 자아 방어의 성숙도를 평가하 였다. 이들은 이렇게 각 집단별로 주된 자아 방어기제를 살펴 봄으로써 각 집단의 적응 행동을 추론해 볼 수 있었다.

$\mathrm{MMPI}$ 는 검사자의 주관성을 배제하고, 각 하위 척도에 해 당하는 방어기제를 측정한다는 점에서 좀 더 객관적인 정보 
를 제공할 수 있는 것이 장점이다. 그러나 개인의 복잡한 무 의식을 몇 가지 척도의 상승으로만 평가하기에는 무리가 있 다. 따라서 실제 임상에서는 투사적 검사와 함께 측정하여 성격적 특성뿐만 아니라 개인의 심리적 갈등과 욕구, 사고 및 정서를 종합적으로 평가하고 있다.

\section{방어기제 평가에 대한 국내 연구 동향}

지난 100 여 년 동안 방어기제에 관한 많은 연구가 있지만 경험적 연구는 그리 활발하지 못하였다. 무의식적 현상이 평 가하기 어렵고, 적절한 평가 방법이 결여되어 있고, 방어기 제를 측정하는 방법에 있어 신뢰도의 난점이 있기 때문이다 (Andrews 등 1993; Vaillant, 1992). 방어와 같은 무의식적 정신 과정에 대한 측정은 매우 어려운 문제로, 측정이 보다 객관적으로 이루어질 수 있지 않는 한 방어에 대한 본격적 경험적 연구를 기대하기 힘든 것이 현실이다. 그러나 방어기 제의 평가와 활용이 정신과 임상에서 중요한 부분인 만큼, 이와 관련된 연구는 계속해서 진행 중이다.

국내에서 방어기제 평가와 관련한 지난 30년간의 연구 동 향을 정리해 보면, 먼저 Kim 등(1991)이 개인의 방어기제를 한국인의 적응 방식과 방어 방식을 평가하기 위해 이화방어 기제검사를 개발하고 표준화 연구를 실시하였다. Suh와 Lee(1997)는 기존에 있었던 융의 단어연상검사에 대한 한국 형 축약 수정안을 개발하였고, 한국과 스위스 피검자군을 대 상으로 한 비교연구를 통해 이를 검증하였다. $\operatorname{Kim}(2003)$ 은 Perry(1990)의 방어기제 평정 척도(DMRS)를 번안하여 대학 생 65명을 대상으로 방어기제를 경험적으로 평가하고, 방어 의 성숙도와 심리 증상의 심각도 수준 간의 관계를 조사하였 다. Kim 등(2005)은 방어의 성숙도와 상담자 개입 간 상호작 용이 상담 성과에 미치는 효과를 분석하기 위해, DMRS를 활용해 21 명의 상담자가 진행한 34 개의 상담 사례를 분석하 였다. 이를 통해 방어의 성숙도에 따라 상담자의 개입 전략 이 달라져야 함을 시사하였다. Kim과 $\mathrm{Ko}(2018)$ 는 Vaillant 의 방어기제 평정 척도(VDMRS)를 바탕으로 한국판 베일런 트 방어기제 평정 척도(K-VDMRS)를 구성하여 타당화 연 구를 시행하였다. Cho(1999)는 기존의 DSQ를 토대로 한국 판 방어 유형 질문지(K-DSQ)를 개발하고 타당화 연구를 시 행하였다. MMPI는 투사적 검사나 면담식 평가 방법에 비해 객관적인 자료를 얻을 수 있다는 점에서 연구적 측면에서 활 용도가 높다. 국내에서는 Pae(1993)가 MMPI의 각 하위 척 도와 방어기제와의 관련성을 연구하였고, Jun과 Park(1995) 은 MMPI 프로파일 유형에 따른 자아 방어기제의 차이에 관 한 연구를 시행하였다. 그 외에도 Park(1993)은 남녀 1,320 명을 대상으로 이화방어기제검사를 시행하였고, 연령별로
성숙 단계별 방어기제의 사용에 유의미한 차이가 있다는 점 을 발견하기도 했다.

\section{결 론}

방어기제는 개인이 스트레스를 처리하고 심리 내부의 평 형 상태를 유지하기 위한 무의식적인 작업 과정이며, 동일한 스트레스 상황에서도 각 개인이 서로 다른 사고와 정서, 행동 을 나타내는 이유이기도 하다. 방어기제의 평가를 통해 한 개 인에 대한 많은 정보를 알아낼 수 있고, 이는 정신과 임상에 서 환자를 보다 잘 이해하기 위한 여러 효과적인 방법 중 하 나이다. 방어기제를 활용하는 데 앞서 이를 어떻게 분류할 것 인지에 대해 많은 논의가 있어 왔지만, 현재로서 가장 널리 받아들여지고 있는 것은 방어의 성숙도에 따른 분류이다. 또 한 방어의 성숙도는 대체로 개인의 적응 수준과 관련이 있다.

방어기제의 평가는 임상에서 환자의 현재 적응 수준을 파 악하고 이를 통해 미래의 정신건강을 예측할 수 있는 하나 의 방법으로써 치료에 적용될 수 있다. 따라서 임상가에게 있어 방어기제를 측정하는 도구에 대한 적절한 이해가 중요 하다. 지금까지 방어기제 평가 검사들에 대해 설명한 바와 같이, 각각의 방법에는 장점과 단점이 있다. 면담을 통한 검 사는 임상가와 상호 관계 속에서 환자의 무의식적 행동의 경향성을 분석한다는 점에서 효과적이지만, 임상가의 재량 과 주관적인 관점이 많이 작용하기 때문에 일관성이 떨어질 수 있다는 단점이 있다. 자가보고 검사의 경우 임상가의 주 관적인 추리가 어느 정도 배제되어 검사의 신뢰도가 높고, 소요 시간이 단축된다는 점에서 좀 더 보완적이나, 임상가와 의 상호작용이 거의 없기 때문에 무의식적 행동을 분석하는 데 한계가 있다. 이와 달리 투사적 검사와 객관적 검사는 방 어기제를 간접적으로 측정하는 검사이다. 이 중 투사적 검사 는 보다 심층적인 심리 내적 정보를 얻을 수 있기 때문에 환 자의 정신역동 평가에 용이하지만, 임상가의 주관적 해석이 많은 영향을 미치고 검사의 표준화가 어렵다는 점이 단점이 다. 실제 임상에서는 이를 보완하기 위해 MMPI와 같은 객 관적 검사가 함께 이뤄지고 있다.

저자들은 논문을 통해 현재 방어기제를 측정하기 위한 어 떤 검사들이 있는지, 각각의 검사가 어떠한 방식으로 이루어 지는지, 그리고 그 의미가 무엇인지를 정리하고자 하였다. 또한 최근 국내의 연구 동향을 파악하여 방어기제 연구가 어느 정도로 이뤄지고 있는지 정보를 제공하고자 하였다. 이 를 통해 임상가들이 실제 사용 가능한 검사들의 종류를 파 악하고 적절한 검사를 사용하는 데 도움이 되었으면 하는 바람이다. 


\section{Acknowledgments}

None

\section{Conflicts of Interest}

The authors have no potential conflicts of interest to disclose.

\section{Author Contributions}

Conceptualization: Jee Hyun Ha. Data curation: Sumin Hong. Formal analysis: Jee Hyun Ha. Funding acquisition: Jee Hyun Ha. Investigation: Jee Hyun Ha. Methodology: Jee Hyun Ha. Project administration: Jee Hyun Ha. Resources: Sumin Hong. Software: Sumin Hong. Supervision: Jee Hyun Ha. Validation: Jee Hyun Ha. Visualization: Jee Hyun Ha. Writing — original draft: Sumin Hong. Writing—review \& editing: Jee Hyun Ha.

\section{ORCID iDs}

Jee Hyun Ha: https://orcid.org/0000-0002-0973-1139

Sumin Hong: https://orcid.org/0000-0002-6109-6902

\section{REFERENCES}

정범모, 이정균, 진위교. MMPI 다면적 인성검사 검사법 요강. 서울: 코 리안테스팅센터;1965.

Andrews G, Pollock C, Stewart G. The determination of defense style by questionnaire. Arch Gen Psychiatry 1989;46:455-460.

Andrews G, Singh M, Bond M. The defense style questionnaire. J Nerv Ment Dis 1993;181:246-256.

Bauer SF, Rockland LH. The inventory of defense-related behaviors-An approach to measuring defense mechanisms in psychotherapy: a preliminary report. In: Conte HR, Plutchik R. Ego defenses: theory and measurement. New York, NY: John Wiley \& Sons;1995. p.300-314.

Beck SJ. Introduction to the Rorschach method: a manual of personality study. American Orthopsychiatric Association Monographs 1937;15: 278.

Bellak L. The thematic apperception test and the children's apperception test in clinical use. New York, NY: Grune \& Stratton;1971.

Beutel M. Bewältigungsprozesse bei chronischen Krankheiten (Coping mechanisms and chronic disease). Weinheim: Edition Medizin, VCH; 1988.

Bond M. An empirical study of defensive styles: the defense style questionnaire. In: Vaillant GE. Ego mechanism of defense: a guide for clinicians and researchers. Washington, DC: American Psychiatric Press, Inc;1992. p.127-158.

Bond M, Gardner ST, Christian J, Sigal JJ. Empirical study of self-rated defense styles. Arch Gen Psychiatry 1983;40:333-338.

Bond M, Perry JC, Gautier M, Goldenberg M, Oppenheimer J, Simand J. Validating the self-report of defense styles. J. Pers 1989;3:101-112.

Bond M, Wesley S. Manual for the defense style questionnaire (DSQ). Montreal: McGill University;1996.

Brenner C. Defense and defense mechanisms. Psychoanal Q 1981;50:557569.

Cho SH. A validation study of Korean version of defense style questionnaire. Korean J Counsel Psychotherapy 1999;11:115-137.

Conte HR, Plutchik R. Ego defenses: theory and measurement. New York, NY: John Wiley \& Sons; 1995.

Cooper SH. The empirical study of defensive processes: a review. In: Barron JW, Eagle MN, Wolitzky DL. Interface of psychoanalysis and psychology. Washington, DC: American Psychological Association; 1992. p.327-346

Cooper SH. Changing notions of defense within psychoanalytic theory. J Pers 1998;66:947-964.

Cramer P. The development of defense mechanisms. J Pers 1987;55:597614.
Cramer P. The development of defense mechanisms: theory, research, and assessment. New York, NY: Springer-Verlag;1991.

Cramer P. Defense mechanisms in psychology today. Further processes for adaptation. Am Psychol 2000;55:637-646.

Deutsch H. The psychology of women: a psychoanalytic interpretation, Vol. 1. NewYork, NY: Grune and Stratton;1944.

Drapeau M, De Roten Y, Perry JC, Despland JN. A study of stability and change in defense mechanisms during a brief psychodynamic investigation. J Nerv Ment Dis 2003;191:496-502.

Engel GL. Psychological development in health and disease. Philadelphia, PA: W.B. Saunders; 1962.

Erikson EH. Inner and outer space: reflections on womanhood. Daedalus 1964;93:582-606.

Exner JE. The Rorschach, a comprehensive system, Volume 1, Basic foundations and principles of interpretation. New York, NY: Wiley; 1986

Freud A. The ego and the mechanisms of defense. London: Horgath;1937.

Freud A. Normality and pathology in childhood: assessments of development. New York, NY: International Universities Press; 1965.

Freud S. The neuro-psychoses of defence. The standard edition of the complete psychological works of Sigmund Freud, Volume III (18931899): early psycho-analytic publications. London: Hogarth Press; 1894. p.41-61.

Freud S. Inhibitions, symptoms and anxiety. SE 20. London: Hogarth Press;1926. p. 77-175.

Furnham A. Lay understandings of defence mechanisms: the role of personality traits and gender. Psychol Health Med 2012;17:723-734.

Gleser GC, Ihilevich D. An objective instrument for measuring defense mechanisms. J Consult Clin Psychol 1969;33:51-60.

Haan N. Proposed model of ego functioning: coping and defense mechanisms in relationship to IQ change. Psychol Monogr 1963;77:1-23.

Haan N. Coping and defense mechanisms related to personality inventories. J Consult Psychol 1965;29:373-378.

Hartmann H. Ego psychology and the problem of adaptation. New York, NY: International Universities Press; 1939.

Hartmann H, Kris E, Loewenstein RM. Papers on psychoanalytic psychology. Psychol Issues 1964;4:1-20.

Hathaway SR, Mckinley JC. A multiphasic personality schedule (Minnesota): I. Construction of the schedule. J Psychol 1940;10:249-254.

Hertz MR. Scoring the Rorschach test with specific reference to "normal detail" category. Am J Orthopsychiatry 1938;8:100-121.

Hibbard S, Porcerelli J. Further validation for the Cramer Defense Mechanism Manual. J Pers Assess 1998;70:460-483.

Ihilevich D, Gleser GC. Defense mechanisms: their classification, correlates, and measurement with the Defense Mechanisms Inventory (DMI Manual). Owosso, MI: DMI Associates;1986.

Johansen PØ, Krebs TS, Svartberg M, Stiles TC, Holen A. Change in defense mechanisms during short-term dynamic and cognitive therapy in patients with cluster C personality disorders. J Nerv Ment Dis 2011; 199:712-715.

Jun HM, Park YS. The relation between MMPI profile types by cluster analysis and defense mechanisms in university students. Kor J Clin Psychol 1995;14:191-199.

Kernberg OF. A psychoanalytic classification of character pathology. J Am Psychoanal Assoc 1970;18:800-822.

Kim JE, Kim JG, Park YS, Lee GH. A standardization study of EWHA defense mechanism test (EDMT). J Korean Neuropsychiatr Assoc 1991;30:582-592.

Kim JW. The study of the maturity of defense mechanism. Korean J Counsel Psychother 2003;15:747-763.

Kim JW, Lee HJ, Lee JH. The relationship among clients' defense maturity, counselors' interventions, and counseling outcomes. Korean J Counsel Psychother 2005;17:91-110.

Kim K, Ko YG. Validation of the Korean version of the vaillant defense 
mechanism rating scale. Kor J Clin Psychol 2018;37:236-251.

Kramer U, De Roten Y, Michel L, Despland JN. Early change in defence mechanisms and coping in short-term dynamic psychotherapy: relations with symptoms and alliance. Clin Psychol Psychother 2009;16: 408-417.

Lazarus RS. The costs and benefits of denial. In: Breznitz S. The denial of stress. New York, NY: International Universities Press;1983. p.1-30.

Mahalik JR, Cournoyer RJ, DeFranc W, Cherry M, Napolitano JM. Men's gender role conflict and use of psychological defenses. J Couns Psychol 1998;45:247-255.

Menninger K, Mayman M, Pruyser P. The vital balance: the life process in mental health and illness. New York, NY: Viking Press;1963.

Moore BE, Fine BD. Psychoanalytic terms and concepts. New Haven, CT: Yale University Press;1990. p.48-49.

Morgan CD, Murray HA. A method for investigating fantasies: the thematic apperception test. Arch NeurPsych 1935;34:289-306.

Pae JY. A study on the relationship between characteristic trait on MMPI subscales and defence mechanism of ego. [dissertation]. Seoul: Ewha Womens University; 1993.

Park YS. A study on psychological ego defense mecanisms differences among age groups. Ewha Med J 1993;16:133-143.

Perry JC. The defense mechanism rating scales manual. Cambridge, MA: Harvard School of Medicine; 1990.

Petraglia J, Thygesen KL, Lecours S, Drapeau M. Gender differences in self-reported defense mechanisms: a study using the new defense style questionnaire-60. Am J Psychother 2009;63:87-99.

Piotrowski ZA. A Rorschach compendium. Psychiatr Q 1947;21:79-101.

Ptacek JT, Smith RE, Dodge KL. Gender differences in coping with stress: when stressor and appraisals do not differ. Pers Soc Psychol Bull 1994;20:421-430.

Shin DG. The assessment of personality structure and dynamics by projective techniques. Journal of Student Guidance Research 1989;7:123137.

Skodol AE, Perry JC. Should an axis for defense mechanisms be included in DSM-IV? Compr Psychiatry 1993;34:108-119.

Snarey JR, Vaillant GE. How lower- and working-class youth become middle-class adults: the association between ego defense mechanisms and upward social mobility. Child Dev 1985;56:899-910.

Suh GH. A study for the abbreviated Korean modification of C. G. Jung's word association test. [dissertation]. Seoul: Seoul National University; 1995.

Suh GH, Lee BY. Comparisons between the association norms of the Korean and the Swiss groups in C. G. Jungs word association test-Some considerations to the sociocultural factors affecting association norms. Shim-Song Yon-Gu 1997;12:129-164.

Trimboli F, Kilgore RB. A psychodynamic approach to MMPI Interpretation. J Pers Assess 1983;47:614-626.

Vaillant GE. Theoretical hierarchy of adaptive ego mechanisms: a 30-year follow-up of 30 men selected for psychological health. Arch Gen Psychiatry 1971;24:107-118.

Vaillant GE. Natural history of male psychological health. III. Empirical dimensions of mental health. Arch Gen Psychiatry 1975;32:420-426.

Vaillant GE. Natural history of male psychological health. V. The relation of choice of ego mechanisms of defense to adult adjustment. Arch Gen Psychiatry 1976:33:535-545.

Vaillant GE, Bond M, Vaillant CO. An empirically validated hierarchy of defense mechanisms. Arch Gen Psychiatry 1986;43:786-794.

Vaillant GE, Schnurr P. What is a case? A 45-year study of psychiatric impairment within a college sample selected for mental health. Arch Gen Psychiatry 1988;45:313-319.

Vaillant GE, Vaillant CO. Natural history of male psychological health, XII. A 45-year study of predictors of successful aging at age 65. Am J Psychiatry 1990;147:31-37.

Vaillant GE. Ego mechanisms of defense: a guide for clinicians and researchers. Washington, DC: American Psychiatric Press;1992.

Watson DC. Predicting psychiatric symptomatology with the defense style questionnaire-40. Int J Stress Manag 2002;9:275-287.

Watson DC, Sinha BK. Gender, age, and cultural differences in the defense style questionnaire-40. J Clin Psychol 1998;54:67-75.

Willick MS. Defense. In: Moore BE, Fine BD. Psychoanalysis: the major concepts. New Haven, CT: Yale University Press;1995. p.485-493.

Zhang L. Defense mechanisms and thinking styles. J Cogn Educ Psychol 2015;14:163-179. 